\title{
Eye movements following autokinesis
}

\author{
JORDAN POLA \\ College of Optometry, State University of New York, New York, New York 10010
}

and

LEONARD MATIN

Columbia University, New York, New York 10027

\begin{abstract}
Eye movements in the dark interval following extinction of an autokinetic target are systematically related to the direction of the target's autokinetic movement.
\end{abstract}

During the course of some experiments on the relation of perceived vernier offset and eye movements (Matin, Matin, \& Pola, Note 1), we found that the direction of autokinetic motion of the fixation target predicted the direction of offset of the two lines within the vernier target that was flashed subsequent to the extinction of the fixation target. This result was obtained with three subjects. Since the experiment was carried out in darkness and the two lines were separated by a variable dark interval $(<1 \mathrm{sec})$, a likely explanation of this connection is that the autokinetic movements were predictive of eye movements that produced an offset between the retinal images of the two lines during the dark interval. In our next experiment in which eye movements were recorded, measurements were made to test this hypothesis. The experiment was carried out using two subjects (one of whom was also used in the previous experiment), but only one reported autokinesis with enough regularity to provide useful data. However, the data were sufficiently interesting and clear in confirming the hypothesis that we describe them briefly here.

Each trial began with $4 \mathrm{sec}$ of fixation on a dim 3.5-min circular target. Four hundred milliseconds following extinction of the fixation target, the lower of the two vertical bars of a vernier target was flashed for $2 \mathrm{msec}$. After a dark interval of either 200 microsec or $50,100,200,300,500$, or $800 \mathrm{msec}$, the upper bar was flashed for $2 \mathrm{msec}$. The subject then reported the direction of fixation-target autokinesis or that no autokinetic movement of the fixation target had occurred, and the direction of offset of the vernier target (upper bar to the left or right of lower bar). Fixation-target autokinesis was reported to one of eight directions: north, northeast, east, southeast, south, southwest, west, or northwest. Since the portion of the experiment relating to the vernier target does not concern

This research was supported by PHS Research Grant EY00375 from the National Eye Institute, National Institutes of Health, and by National Science Foundation Grants NSF GB5947 and NSF BMS73-01463. Address reprint requests to Visual Science Laboratory, Department of Psychology, Schermerhorn Hall, Columbia University, New York, New York 10027. us here, we will not describe it further (see Matin, 1972, for a preliminary report). Horizontal eye movements were recorded by a contact-lens technique using infrared light (Matin, 1964; Matin \& Pearce, 1964), and the average eye position during each of the two $2-\mathrm{msec}$ flashes was electronically obtained on-line from the recordings of eye position by use of a modified Beckman counter (6144) and digital volt meter (651). The data on eye position and the reports of autokinesis provide the measurements for the present report. Two hundred trials were obtained at each dark interval. These were collected in 14 experimental sessions. Within each session, a total of 100 trials was obtained with 50 trials at each of two of the values of the dark interval. Within a session, the measurements at one dark interval were completed before going on to another. Each dark interval was tested first in two of the four sessions in which it was employed and second in two others. In each of the four sessions in which a given dark interval was used, it was paired with a different dark interval, and the 4 days in which the sessions for a given dark interval were run were spaced out fairly evenly. These aspects of design were aimed at minimizing any confounding of our main variables with variation that might be systematic with temporal factors that operated within or across sessions. The subject viewed the targets in complete darkness at a distance of $8 \mathrm{ft}$; his head was stabilized with a mouthbite.

Figure 1 shows the magnitude of the horizontal eye movement between the two 2 -msec periods in which the vernier lines were presented; these were averaged across trials. The average value was plotted as a function of the dark interval between the two flashes separately for trials in which autokinesis was to the left (west, northwest, or southwest), trials in which autokinesis was to the right (east, northwest, or southeast), and trials in which autokinesis was neither east nor west (north, south, or did not occur). Leftward autokinesis was followed by a substantial rightward eye movement whose magnitude increased monotonically with time. Rightward autokinesis was followed by eye movements whose average value did not put the eye far from the original fixation position or change much throughout 


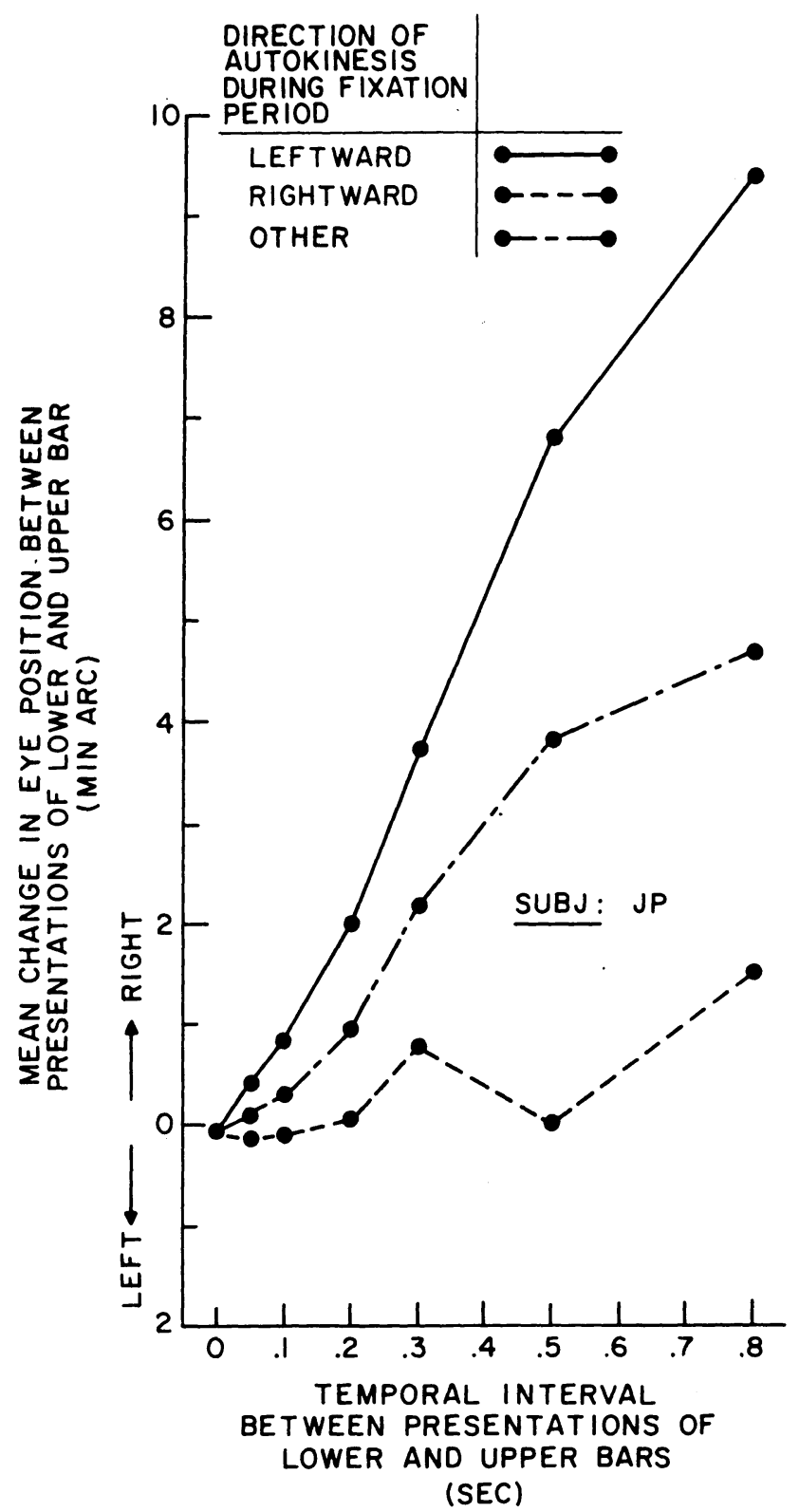

Figure 1. Mean change in eye position in the dark interval. The data are separated into groups that depend on direction of autokinesis for prior fixation target.

the $800-\mathrm{msec}$ range of measurement. The remaining trials in which autokinesis was neither leftward nor rightward fell between the two, increasing monotonically to the right with dark interval but less rapidly than on
Table 1

Distribution of Autokinetic Direction for Each Dark Interval

\begin{tabular}{cccc}
\hline Dark Interval & Leftward & Other & Rightward \\
\hline $200 \mathrm{microsec}$ & 106 & 23 & 61 \\
$50 \mathrm{msec}$ & 75 & 49 & 69 \\
$100 \mathrm{msec}$ & 101 & 24 & 38 \\
$200 \mathrm{msec}$ & 90 & 53 & 39 \\
$300 \mathrm{msec}$ & 105 & 39 & 38 \\
$500 \mathrm{msec}$ & 47 & 45 & 82 \\
$800 \mathrm{msec}$ & 78 & 43 & 64 \\
\hline
\end{tabular}

trials in which autokinesis was leftward. Of course, on a substantial number of trials at each dark interval the change in eye position was not in the direction of the average shown in Figure 1. Since some trials had to be discarded for present purposes as a consequence of a failure in triggering the counter-digital volt-meter combination, less than 200 trials were obtained at each dark interval. Although some differences in autokinetic distribution with dark interval were present (Table 1), they did not appear to be systematic and, hence, were not confounded in the relation between autokinetic direction and the direction of eye movement.

\section{REFERENCE NOTE}

1. Matin. L.. Matin. E., \& Pola, J. Detection of vernier offiset. el'e movements, and autokinetic movement. Paper presented at meeting of Eastern Psychological Association. 1968.

\section{REFERENCES}

Matin. L. Measurement of eye movements by contact-lens techniques: Analysis of measuring systems and some new methodology for three-dimensional recording. Journal of the Optical Society of America. 1964. 54, 1008-1018.

Matin. L. Eye movements and perceived visual direction. In D. Jameson \& L. M. Hurvich (Eds.), Handbook of sensony phisiology: Visual psychophysics (Vol. VIl/4). Berlin: Springer-Verlag. 1972. Pp. 331-380.

Matin. L.. \& Pearce. D. G. Three-dimensional recording of rotational eve movements by a new contact-lens technique. In W. E. Murry \& P. F. Salisbury (Eds.). Biomedical sciences instrumentation. New York: Plenum. 1964. Pp. 79.95.

(Received for publication July 18. 1977.) 